\title{
The Urgent Need of Reliable and Approved Vaccination for COVID-19 Novel Corona Virus in Current Pandemic
}

\author{
Ahsan Siddiqui, M.D, M.S.P.H (UK)* \\ Department of Quality Management \& Patient Safety, General Directorate of Health, Saudi Arabia
}

*Corresponding author: Ahsan Ali Siddiqui, Consultant Epidemiologist, Quality Management \& Patient Safety, Department, General Directorate of Health, Riyadh Saudi Arabia

ARTICLE INFO

Received: 㓞 June 01, 2020

Published: 幽 June 12, 2020

Citation: Ahsan Ali Siddiqui. The Urgent Need of Reliable and Approved Vaccination for COVID-19 Novel Corona Virus in Current Pandemic. Biomed J Sci \& Tech Res 28(2)-2020. BJSTR. MS.ID.004623.

Keywords: COVID-19 Vaccine; WHO; Antibody; Antibody-Dependent Enhancement; Mucosal Immunization; Sars-Cov-2; Pandemic; Viral Genomics; Coronavirus; Outbreak; Infection; Repurposed Therapies; Middle East Respiratory Syndrome Coronavirus; Antiviral Therapy; Coronavirus Vaccines; Severe Acute Respiratory Syndrome Coronavirus (Sars-Cov); Virologic Diagnosis
ABSTRACT

Background and Objective: The aim of this Article is to describe the efforts made by current Medical, Scientific and Pharmaceutical organizations to urgently prepare the Vaccine for COVID-19 Pandemic. Current news and announcements say that at the end of the year in December 2020 or later Vaccine for COVID-19 might be available for the public.

Methods: The Methodology used in this Article is Critical Literature review where Author has presented the Table 1 which critically Analyze 15 randomly selected articles. Critical analysis focuses on presenting the Importance of "Urgent Need of reliable and approved Vaccination for COVID-19 Novel corona Virus in current Pandemic.". The word "COVID-19 Vaccines" is used as search word in PUBMED, Google Others searches to trace the articles and bring it for Critical Literature review results.

Results: Author of this article have presented the results by using diagrams from SPSS19 software. After studying and carefully critically reviewing the 21 Articles and other sources and randomly selecting 15 Articles for Urgent Need of reliable and approved Vaccination for COVID-19. First part of the result in Table 1 and SPSS Diagram 1 clearly shows that all 15 randomly selected articles agreed on the urgent need for the production and availability of COVID-19 Vaccine. The second part of the result shows in SPSS Diagram 2 that 12 articles from 15 agrees 100 Percent whereas 3 articles did not discuss the urgent availability of COVID-19 Vaccine.

Conclusion: After seeing the Disaster resulting from COVID-19 Pandemic in last five months all over the world, where almost 370,000 people died and approximately 6 Million people are sick due to COVID-19. There is urgent need of VACCINE of COVID-19 Pandemic and there is news that may be Vaccine could be available in December 2020 or later. The lesson learned is that we in Twenty first century do not have capability to develop immediate Medicines or Vaccines for new disease. Medical Scientists need to study more and Medical Science need more hard work to learn the diseases and their urgent treatment.

\section{Introduction}

More than 90 vaccines [1] are being developed against SARSCoV-2 by research teams in companies and universities across the world. Researchers are trialing different technologies some of which haven't been used in a licensed vaccine before. At least six groups have already begun injecting formulations into volunteers in safety trials others have started testing in animals. Nature's graphical guide explains each vaccine design. All vaccines aim to expose the body to an antigen that won't cause disease but will provoke an immune response that can block or kill the virus if a person becomes infected. There are at least eight types being tried against the coronavirus, and they rely [1] on different viruses or viral parts. The global COVID-19 vaccine [2] R\&D landscape includes 115 vaccine candidates of which 78 are confirmed as active and 37 are unconfirmed development status cannot be determined from publicly available or proprietary information sources. Of the 78 confirmed active projects 73 are currently at exploratory or preclinical stages. The most advanced candidates 
have recently moved into clinical development including mRNA1273 from Moderna, Ad5-nCoV from CanSino Biologicals INO4800 from Inovio and LV-SMENP-DC and pathogen-specific aAPC from Shenzhen Geno-Immune Medical Institute. Numerous other vaccine developers have indicated [2] plans to initiate human testing in 2020.

Sharing knowledge with $[3,4]$ parallel COVID-19 vaccine efforts worldwide is crucial. WHO is in the process of creating a forum for everyone who is developing COVID-19 vaccines to come together and present their plans and initial findings? It is essential that we all measure immunological responses to the various vaccines in the same way to ensure comparability and generalizability of our collective findings. Work is continuing at a very fast pace and I am in no doubt that we will see an unprecedented spirit of collaboration and cooperation convened by WHO as we move towards a shared [4] global goal of COVID-19 prevention through vaccination (Figure 1). The G7 committed to [5] supporting the launch of joint research projects for COVID-19 treatments and vaccines.12 High-level dialogue is needed on ways to ensure complementarity of efforts and global access to COVID-19 vaccines. Investments should proceed in tandem to build national systems for delivery of potential vaccines for example using domestic financing and external financing from the World Bank Group's \$14 billion COVID-19 Fast Track Facility13 and reallocations from the Global Fund to Fight AIDS Tuberculosis and Malaria Gaviand [5] Global Financing Facility grants for service delivery (Figure 2).

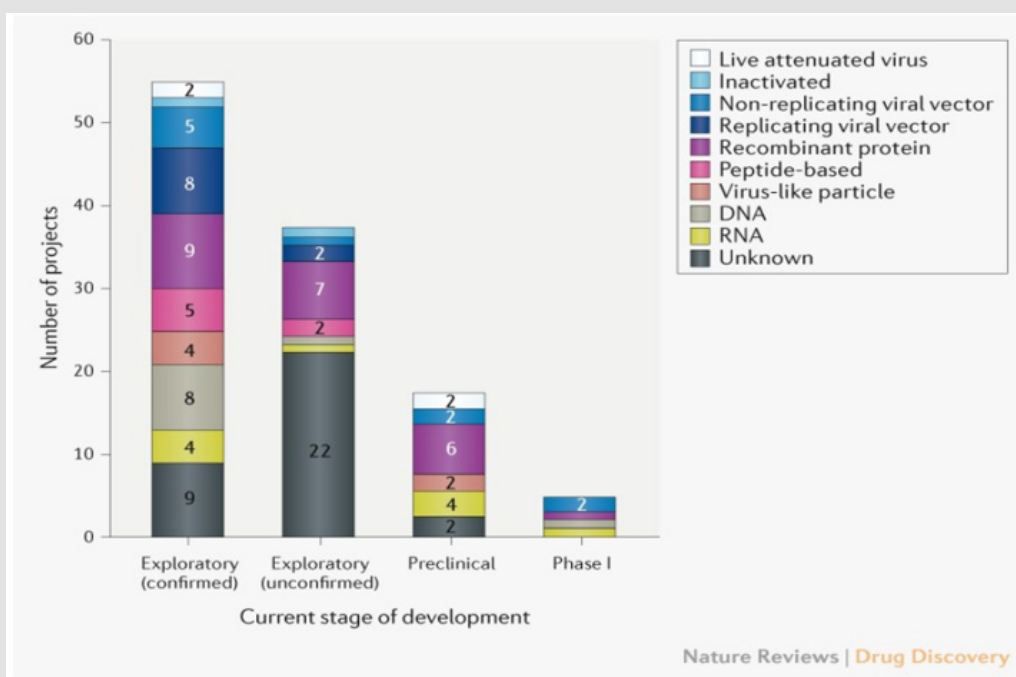

Fig. 1 | Pipeline of COVID-19 vaccine candidates by technology platform. Exploratory projects (split into confirmed and unconfirmed) are in the early planning stage with no in-vivo testing, and preclinical projects are at the stage of in-vivo testing and/or manufacturing clinical trials material.

Figure 1: (Tung Le, Zacharias Andreadakis, Arun Kumar, et al. 2020).

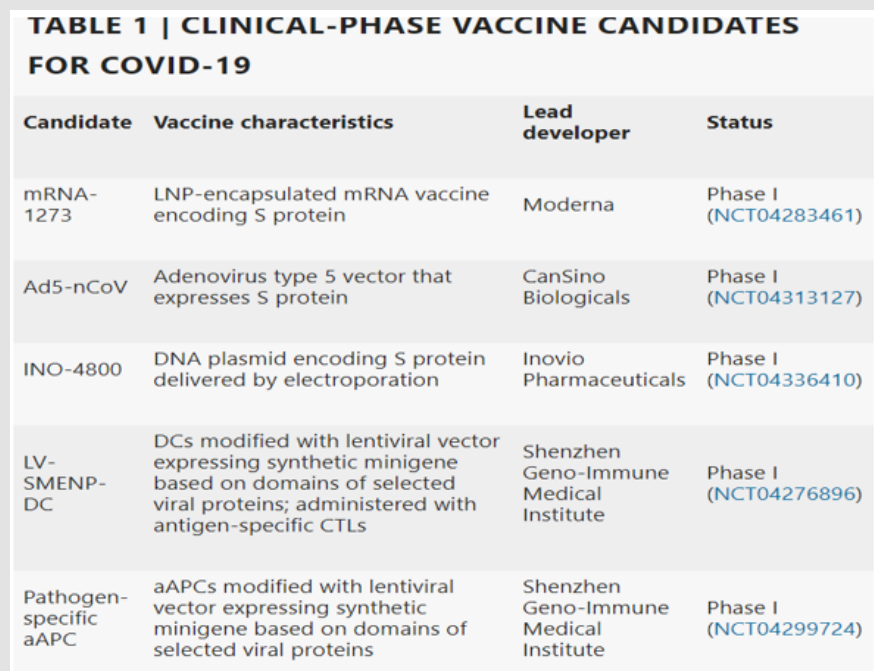

APC artificial antigen-presenting cell: CTL cytotoxic T lymphocyte: DC, dendritic cell: LNP, lipid nanoparticle; S protein, SARS-CoV-2 spike protein. Source: ClinicalTrials.gov website;

Figure 2: (Tung Le, Zacharias Andreadakis, Arun Kumar et al, 2020). 
One of the crucial mistakes [6] made at the time by French authorities was to refuse to communicate early on the measures taken to ensure the safety of the vaccine for fear that the mere evocation of risk might provoke irrational reactions. This approach let critics set the agenda on this issue condemning public authorities to a defensive position. Public authorities are setting up fast-track approval processes for a putative [6-10] vaccine against SARS-CoV-2.9 It is crucial to communicate early and transparently on these processes to avoid vaccines becoming part of political debates. As the world is witnessing the [11] epidemic of COVID-19 a disease caused by a novel coronavirus SARS-CoV-2 emerging genetics and clinical evidences suggest a similar path to those of
SARS and MERS. The rapid genomic sequencing and open access data together with advanced vaccine technology are expected to give us more knowledge on the pathogen itself including the host immune response as well as the plan for therapeutic vaccines in the near future. This review aims to provide a comparative view among SARS-CoV MERS-CoV and the newly epidemic SARS-CoV-2 in the hope to gain a better understanding of the host-pathogen interaction host immune responses and the pathogen immune evasion strategies. This predictive view may help in designing an immune intervention or preventive [11] vaccine for COVID-19 soon (Figures 3\&4).

\begin{tabular}{|c|c|c|c|}
\hline & SARS-CoV & MERS-CoV & SARS-CoV-2 \\
\hline \multicolumn{4}{|l|}{ Demographic } \\
\hline Date/Place first detected & $\begin{array}{l}\text { November 2002/ } \\
\text { Guangdong China }\end{array}$ & $\begin{array}{l}\text { June, } 2012 / \\
\text { Jeddah, Saudi Arabia }\end{array}$ & $\begin{array}{l}\text { December, 2019/ } \\
\text { Wuhan, China }\end{array}$ \\
\hline Age, years (range) & 39.9 (1 to 91$)$ & $56(14$ to 94$)$ & $<1$ to $>80^{10.17}$ \\
\hline Confirmed cases & 8,096 & 2,494 & $75,725^{*}$ \\
\hline Mortality rate & $744(9.19 \%)$ & $858(34.4 \%)$ & $2,126(2.8 \%)^{*}$ \\
\hline \multicolumn{4}{|l|}{ Host-Pathogen Interaction } \\
\hline Possible natural reservoir & Bat & Bat & Bat \\
\hline Possible intermediate host & Palm civets & Camel & Pangolin** \\
\hline Predominant cellular receptor & ACE2 & $\begin{array}{l}\text { Dipeptidyl peptidase } 4 \\
\text { (DPP4, also known as } \\
\text { CD26) }\end{array}$ & ACE2 2 \\
\hline \multicolumn{4}{|l|}{ Emerging characteristic } \\
\hline Number of affected country & 29 & 27 & $29^{\circ}$ \\
\hline Reproductive number, $R_{\ominus}$ & $1.4-5.5$ & $<1$ & $2.2-2.6$ \\
\hline Epidemic doubling time & $\begin{array}{l}4.6 \text { to } 14.2 \text { days } \\
\text { (depending on } \\
\text { settings) }\end{array}$ & $90^{\text {s }}$ & $6.4^{15}$ \\
\hline
\end{tabular}

Figure 3: (EakachaiPrompetchara, ChutitornKetloy, TanapatPalaga, 2020).

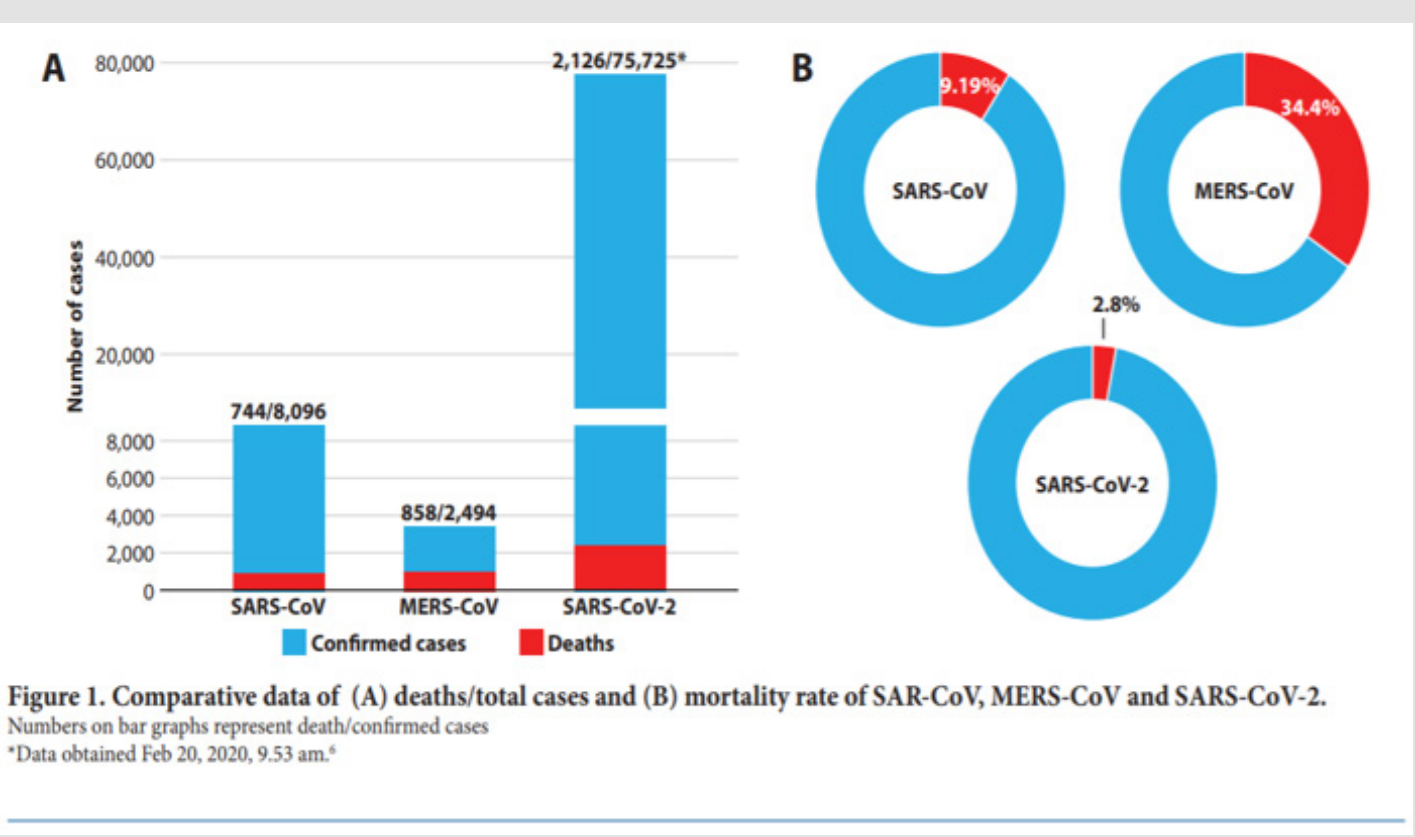

Figure 4: (Eakachai Prompetchara, Chutitorn Ketloy, Tanapat Palaga, 2020). 
To address this global crisis [12] up-to-date information on viral genomics and transcriptomics is crucial for understanding the origins and global dispersion of the virus providing insights into viral pathogenicity transmission and epidemiology and enabling strategies for therapeutic interventions drug discovery and vaccine development. Therefore, this review provides a comprehensive overview of COVID-19 epidemiology genomic etiology findings from recent transcriptomic map analysis viral-human protein interactions molecular diagnostics and the current status of vaccine and novel therapeutic intervention development. Moreover, we provide an extensive list of resources that will help the scientific community access numerous types of databases related to SARSCoV-2 OMICs and [12] approaches to therapeutics related to COVID-19 treatment.

\section{Methods}

The Methodology used in this Article is Critical Literature review where Author has presented the Table 1 which critically Analyze 15 randomly selected articles. Critical analysis focuses on presenting the Importance of "Urgent Need of reliable and approved Vaccination for COVID-19 Novel corona Virus in current Pandemic.". The word "COVID-19 Vaccines" is used as search word in PUBMED, Google Others searches to trace the articles and bring it for Critical Literature review results. There are currently no [8] SARS-CoV-2-specific treatments or vaccines available due to the novelty of the virus. Hence rapid development of effective vaccines against SARS-CoV-2 are urgently needed. Here we developed a pilot-scale production of a purified inactivated SARS-CoV-2 virus vaccine candidate PiCo Vacc which induced SARS-CoV-2-specific neutralizing antibodies in mice rats and non-human primates. These antibodies neutralized 10 representative SARS-CoV- 2 strains suggesting a possible broader neutralizing ability against SARSCoV-2 strains. Three immunizations using two different doses $3 \mu \mathrm{g}$ or $6 \mu \mathrm{g}$ per dose provided partial or complete protection in macaques against SARS-CoV-2 challenge respectively without observable antibody-dependent enhancement of infection [8]. These data support clinical development of SARS-CoV-2 vaccines for humans.

The rapid emergence of (Michael Diamond, Theodore Pierson, 2020) a highly pathogenic readily transmissible coronavirus has resulted in a global pandemic affecting millions and destabilizing economies. This catastrophe triggered a clarion call for the immediate deployment of a protective vaccine. We describe the unique challenges of developing a vaccine against (Michael Diamond, Theodore Pierson, 2020) SARS-CoV-2 in a pandemic setting (Table 1). As COVID-19 has triggered [13] enormous human casualties and serious economic loss posing global threat an understanding of the ongoing situation and the development of strategies to contain the virus's spread are urgently needed. Currently various diagnostic kits to test for COVID-19 are available and several repurposing therapeutics for COVID-19 have shown to be clinically effective. In addition, global institutions and companies have begun to develop vaccines for the prevention of COVID-19. Here we review the current status of epidemiology [13] diagnosis treatment and vaccine development for COVID-19.

a. Measure and statistical Analysis:(IBM (2006) IBM SPSS Software USA.) (Figures 5\&6)[14].

Table 1: 15 Randomly selected Articles to show the Importance of Urgent Need of reliable and approved Vaccination for COVID-19 Pandemic.

\begin{tabular}{|c|c|c|c|c|}
\hline S.NO & $\begin{array}{l}\text { Complete Reference of the Articles selected } \\
\text { for study }\end{array}$ & $\begin{array}{l}\text { Study favors the } \\
\text { Importance of Urgent } \\
\text { Need of reliable and } \\
\text { approved Vaccination for } \\
\text { COVID-19 Pandemic. -YES }\end{array}$ & $\begin{array}{l}\text { Study ignores the } \\
\text { Importance of Urgent } \\
\text { Need of reliable and } \\
\text { approved Vaccination for } \\
\text { COVID-19 Pandemic. -No }\end{array}$ & $\begin{array}{l}\text { Percentages\% of Articles } \\
\text { agreed the Importance of } \\
\text { Urgent Need of reliable } \\
\text { and approved Vaccination } \\
\text { for COVID-19 Pandemic. }\end{array}$ \\
\hline 1 & $\begin{array}{l}\text { Ewen Callaway (2020) The Race for Coronavirus } \\
\text { Vaccines: A Graphical Guide. NATURE Journal. } \\
2020 \text { Apr;580(7805):576-577. doi: 10.1038/ } \\
\text { d41586-020-01221-y. }\end{array}$ & YES & ------- & $100 \%$ \\
\hline 2 & $\begin{array}{c}\text { Tung Le, Zacharias Andreadakis, Arun Kumar et } \\
\text { al (2020) The COVID-19 Vaccine Development } \\
\text { Landscape. Nature Reviews Drug Discovery. } 2020 \\
\text { May;19(5):305-306. doi: } 10.1038 / d 41573-020- \\
\text { 00073-5. }\end{array}$ & YES & ------- & $100 \%$ \\
\hline 3 & $\begin{array}{l}\text { Nicole Lurie, Melanie Saville, Richard H et } \\
\text { al (2020) Developing Covid-19 Vaccines at } \\
\text { Pandemic Speed. The New England Journal of } \\
\text { Medicine. 2020 May 21;382(21):1969-1973. doi: } \\
\text { 10.1056/NEJMp2005630. Epub 2020 Mar 30. }\end{array}$ & YES & ------ & $70 \%$ \\
\hline 4 & $\begin{array}{l}\text { Richard Lane (2020) Sarah Gilbert: Carving a } \\
\text { Path Towards a COVID-19 Vaccine. LANCET } \\
\text { London England. 2020 Apr 18;395(10232):1247. } \\
\text { doi: } 10.1016 / \text { S0140-6736(20)30796-0. }\end{array}$ & YES & ------. & $100 \%$ \\
\hline
\end{tabular}




\begin{tabular}{|c|c|c|c|c|}
\hline 5 & $\begin{array}{l}\text { Gavin Yamey, Marco Schäferhoff, Richard H et } \\
\text { al. (2020) Ensuring Global Access to COVID-19 } \\
\text { Vaccines. LANCET London England. 2020 May } \\
\text { 2;395(10234):1405-1406. doi: 10.1016/S0140- } \\
\text { 6736(20)30763-7. }\end{array}$ & YES & ------ & $100 \%$ \\
\hline 6 & $\begin{array}{l}\text { COCONEL Group (2020) A Future Vaccination } \\
\text { Campaign Against COVID-19 at Risk of Vaccine } \\
\text { Hesitancy and Politicization. The Lancet } \\
\text { Infectious Diseases. } 2020 \text { May 20; S1473- } \\
3099(20) 30426-6 \text {. doi: } 10.1016 / \text { S1473- } \\
3099(20) 30426-6 \text {. }\end{array}$ & YES & ------- & $100 \%$ \\
\hline 7 & $\begin{array}{l}\text { Krishna Ella, V Mohan (2020) Coronavirus } \\
\text { Vaccine: Light at the End of the Tunnel. Indian } \\
\text { Pediatrics Journal. } 2020 \text { May 15;57(5):407-410. } \\
\text { doi: } 10.1007 / \mathrm{s} 13312-020-1812 \text {-z. }\end{array}$ & YES & ------- & $100 \%$ \\
\hline 8 & $\begin{array}{c}\text { Qiang Gao, Linlin Bao, Haiyan M et al (2020) } \\
\text { Rapid Development of an Inactivated Vaccine } \\
\text { Candidate for SARS-CoV-2. SCIENCE New York } \\
\text { NY. } 2020 \text { May 6; eabc1932. doi: 10.1126/science. } \\
\text { abc1932. }\end{array}$ & YES & ------- & $100 \%$ \\
\hline 9 & $\begin{array}{l}\text { Michael Diamond, Theodore Pierson (2020) } \\
\text { The Challenges of Vaccine Development Against } \\
\text { a New Virus During a Pandemic. Cell Host and } \\
\text { Microbe. 2020 May 13;27(5):699-703. doi: } \\
\text { 10.1016/j.chom.2020.04.021. }\end{array}$ & YES & ------- & $100 \%$ \\
\hline 10 & $\begin{array}{l}\text { Limin Yang, Deyu Tian, Wenjun Liu et al (2020) } \\
\text { Strategies for Vaccine Development of COVID-19. } \\
\text { CNKI.net Review. } 2020 \text { Apr 25;36(4): 593-604. }\end{array}$ & YES & ------- & $100 \%$ \\
\hline 11 & $\begin{array}{l}\text { EakachaiPrompetchara, ChutitornKetloy, } \\
\text { TanapatPalaga (2020) Immune Responses } \\
\text { in COVID-19 and Potential Vaccines: Lessons } \\
\text { Learned from SARS and MERS Epidemic. Asian } \\
\text { Pacific Journal of Allergy and Immunology. } 2020 \\
\text { Mar;38(1):1-9. doi: 10.12932/AP-200220-0772. }\end{array}$ & YES & ------ & $80 \%$ \\
\hline 12 & $\begin{array}{c}\text { Mohammed Uddin, Farah Mustafa, Tahir Rizvi et } \\
\text { al (2020) SARS-CoV-2/COVID-19: Viral Genomics, } \\
\text { Epidemiology, Vaccines, and Therapeutic } \\
\text { Interventions. MDPI Viruses. } 2020 \text { May 10;12(5): } \\
\text { E526. doi: } 10.3390 / v 12050526 .\end{array}$ & YES & ------ & $100 \%$ \\
\hline 13 & $\begin{array}{l}\text { Dae-GyunAhn, Hye-Jin Shin, Mi-Hwa Kim et } \\
\text { al (2020) Current Status of Epidemiology, } \\
\text { Diagnosis, Therapeutics, and Vaccines for Novel } \\
\text { Coronavirus Disease } 2019 \text { (COVID-19). The } \\
\text { Journal of Microbiology and Biotechnology } \\
\text { (JMB). 2020 Mar 28;30(3):313-324. doi: } \\
\text { 10.4014/jmb.2003.03011. }\end{array}$ & YES & ------ & $80 \%$ \\
\hline 14 & $\begin{array}{l}\text { HaneenAmawi, Ghina'aDeiab, AlaaAljabali et } \\
\text { al (2020) COVID-19 Pandemic: An Overview of } \\
\text { Epidemiology, Pathogenesis, Diagnostics and } \\
\text { Potential Vaccines and Therapeutics. FUTURE } \\
\text { SCIENCE, THERAPEUTIC DELIVERY. } 2020 \\
\text { Apr;11(4):245-268. doi: } 10.4155 / \text { tde-2020- } \\
\text { 0035. }\end{array}$ & YES & ------ & $100 \%$ \\
\hline 15 & $\begin{array}{l}\text { Zi-Wei Ye, Dong-Yan Jin (2020) Diagnosis, } \\
\text { Treatment, Control and Prevention of SARS- } \\
\text { CoV-2 and Coronavirus Disease 2019: Back } \\
\text { to the Future. CNKI.net, Chinese Journal of } \\
\text { Biotechnology. } 2020 \text { Apr 25;36(4): 571-592. }\end{array}$ & YES & ------ & $1000 \%$ \\
\hline
\end{tabular}




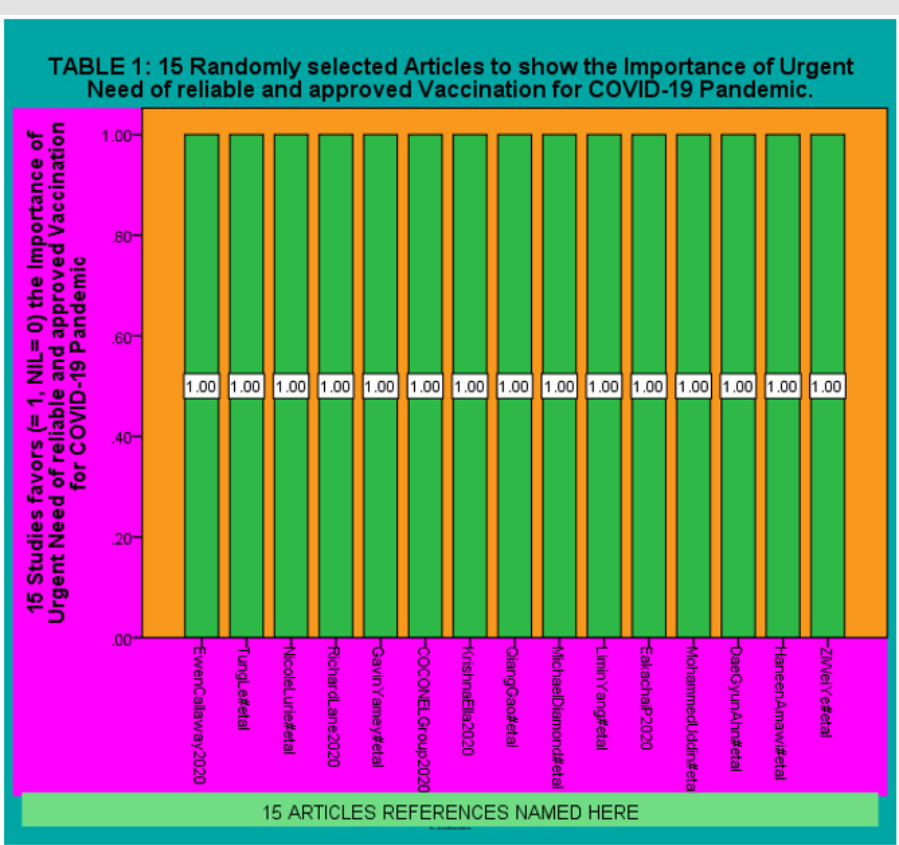

Figure 5: SPSS Diagram 1: (IBM (2006) IBM SPSS Software USA).

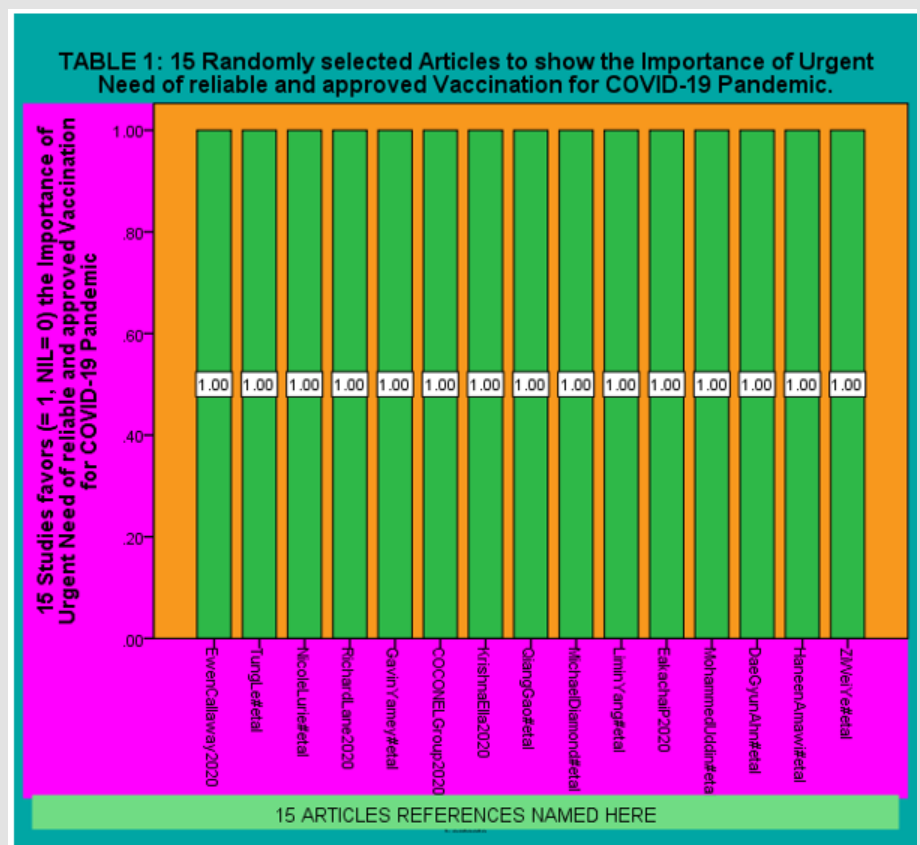

Figure 6: SPSS Diagram 2: (IBM (2006) IBM SPSS Software USA).

\section{Results}

Author of this article have presented the results by using diagrams from SPSS19 software. After studying and carefully critically reviewing the 21 Articles and other sources and randomly selecting 15 Articles for Urgent Need of reliable and approved Vaccination for COVID-19. First part of the result in Table 1 and SPSS Diagram 1 clearly shows that all 15 randomly selected articles agreed on the urgent need for the production and availability of COVID-19 Vaccine. The second part of the result shows in SPSS
Diagram 2 that 12 articles from 15 agrees 100 Percent whereas 3 articles did not discuss the urgent availability of COVID-19 Vaccine. The speed of both the (Limin Yang, Deyu Tian, Wenjun Liu etal, 2020) geographical transmission and the sudden increase in numbers of cases is much faster than SARS and Middle East respiratory syndrome (MERS). COVID-19 is the first global pandemic caused by a coronavirus which outbreaks in 211 countries/territories/areas. The vaccine against COVID-19 regarded as an effective prophylactic strategy for control and prevention is being developed in about 90 institutions worldwide. 
The experiences and lessons encountered in the previous SARS and MERS vaccine research can be used for reference in the development of COVID-19 vaccine. The present paper hopes to provide some (Limin Yang, Deyu Tian, Wenjun Liu et al, 2020) insights for COVID-19 vaccines researchers. This review highlights the [15] preventive measures available clinical therapies and the potential of vaccine development against SARS-CoV-2 by taking into consideration the strong genetic similarities of the 2003 epidemic
SARS-CoV. Recent studies are investigating the repurposing of US FDA-approved drugs as there is no available vaccine yet with many attempts under clinical evaluation. Several antivirals antimalarials and immunomodulators that have shown activity against SARS$\mathrm{CoV}$ and Middle East coronavirus respiratory syndromes are being evaluated. In particular hydroxy chloroquine, remdesivir, favipiravir, arbidol, tocilizumab and bevacizumab [15] have shown promising results (Figure 7).

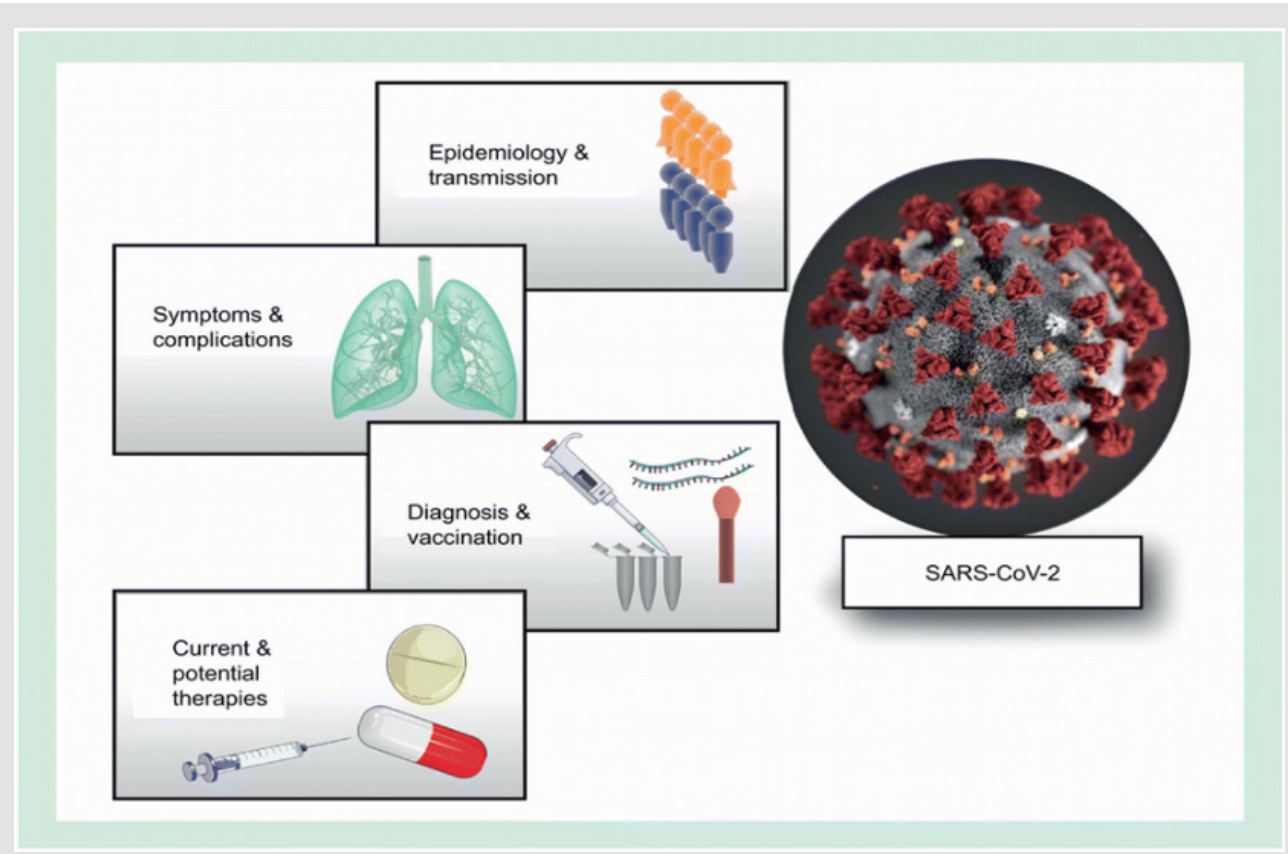

Figure 7: (HaneenAmawi, Ghina'aDeiab, AlaaAljabali et al. 2020).

\section{Discussion}

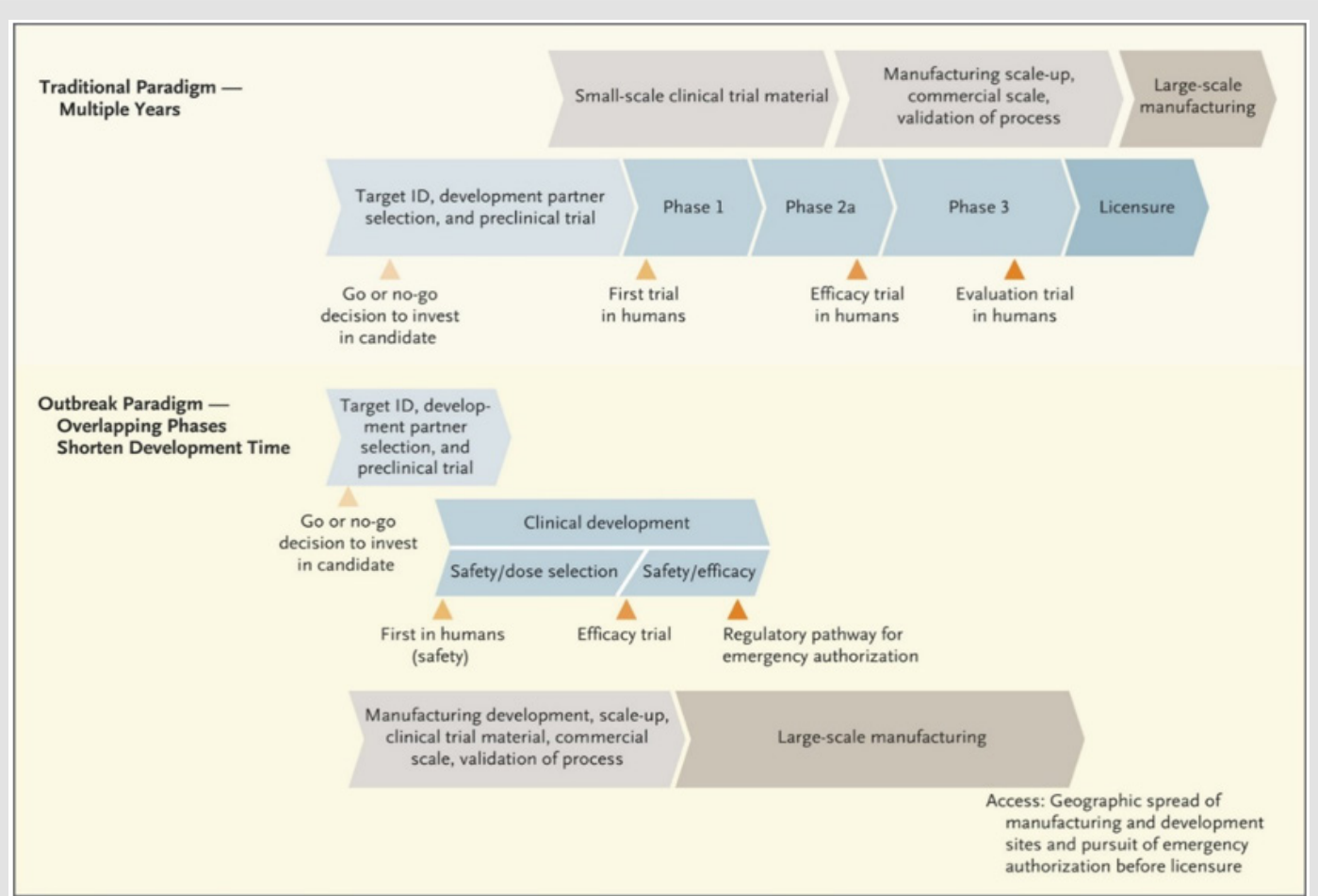

Figure 8: (Nicole Lurie, Melanie Saville, Richard H et al, 2020). 
Predicting the next source of the [7] pandemic can be very challenging. As vaccination is the best way to prevent an infectious disease the development of an effective vaccine against SARSCoV-2 can not only reduce the morbidity and mortality associated with it but can also lessen the economic impact. As the traditional method of vaccine development takes many years for a vaccine to be available to the society the vaccine development for SARS-CoV-2 should be speeded up using a pandemic approach with fast-track approvals from the regulatory authorities. Various challenges associated with developing a vaccine during the pandemic such as technological hurdles clinical development pathways regulatory issues, and support from global [7] funding agencies are expressed here (Figure 8). Significant progress [16] has been made in the study of SARS-CoV and MERS-CoV concerning their natural origins pathogenesis antiviral development and vaccine design. Since SARS-CoV-2 and SARS-CoV are closely related previous findings on SARS-CoV are highly relevant to a better understanding as well as diagnosis treatment prevention and control of SARS-CoV-2.

In this review we highlight recent progresses in the field compare the biological characteristics of SARS-CoV and SARSCoV-2 summarize the urgently-needed diagnostic treatment prevention and control options and provide future perspectives for the outcome of the outbreak and research questions to be answered including some of the difficulties in vaccine development. Hopefully our comments and suggestions would prove useful for the control of the [16] SARS-CoV-2 epidemic in China and the world. The outbreak has led to [17] severe impacts on social health and the economy at various levels. This paper is a review of the significant continuous global effort that was made to respond to the outbreak in the first 75 days. Although no vaccines have been discovered yet a series of containment measures have been implemented by various governments especially in China in the effort to prevent further outbreak whilst various medical treatment approaches have been used to successfully treat infected patients. On the basis of current studies, it would appear that the combined antiviral treatment has shown the highest success rate. This review aims to critically summarize the most recent advances in understanding the coronavirus as well as the [17] strategies in prevention and treatment.

Preliminary evidence suggests [18] children are just as likely as adults to become infected with SARS-CoV-2 but are less likely to be symptomatic or develop severe symptoms. However, the importance of children in transmitting the virus remains uncertain. Most children with SARS-CoV present with fever but this is not the case for the other novel CoVs. Many children affected by MERS-CoV are asymptomatic. The majority of children infected by novel CoVs have a documented household contact often showing symptoms before them. In contrast, adults more often have a nosocomial exposure. In this review we summarize epidemiologic clinical and diagnostic findings as well as treatment and prevention options for common circulating and novel CoVs [17] infections in humans with a focus on infections in children. The vaccine Haller (Jon Cohen, 2020) volunteered to test is made by Moderna a well-financed biotech that has yet to bring a product to market. Moderna and China's Can Sino Biologics are the first to launch small clinical trials of vaccines against coronavirus disease 2019 COVID-19 to see whether they are safe and can trigger immune responses. The CanSino vaccine trial also began on 16 March according to researchers from the Chinese military's Institute of Biotechnology which is collaborating on it. As Science went to press a World Health Organization tally of other $[19,20]$ vaccine candidates that could follow stood at 52 .

In the midst of a pandemic it is [21] reasonable to require certain qualities in candidate vaccines as described above and to start phase 1 clinical trials based on preliminary immunogenicity in animals and expanded trials based on human immunogenicity and evidence of protection in animal models. Justifying expansion to thousands of subjects in efficacy trials that is phase 2 and 3 trials could include additional evidence of vaccine safety in animals immunized with limiting doses of vaccine and breakthrough infections after SARS-CoV-2 challenge. Judicious evaluation of candidate vaccines in healthy adults in parallel with vaccine studies in animal models and coincident process development to scale-up production capacity provides a path forward with minimal risk to human subjects and the potential for enormous benefit through accelerated [21,22] COVID-19 vaccine availability.

The rapidly developing covid-19 epidemic [20] has stimulated an enormous effort to develop vaccines against the coronavirus SARS-CoV-2. At least six vaccine candidates have entered clinical trials across the globe with more than 80 other candidates reported to be in preclinical stages. However, the road to successful vaccine licensure is treacherous and only a handful of these vaccines may make it. No vaccines are currently licensed for any of the other coronaviruses affecting humansSARS-CoV-1 MERS-CoV and minor cold viruses. Economic reasons are undoubtedly a major factor for the absence of these vaccines but vaccine design is also a challenge immune response to (Sarah Caddy, 2020) natural coronavirus infections can be short lived.

\section{Conclusion}

After seeing the Disaster resulting from COVID-19 Pandemic in last five months all over the world, where almost 370,000 people died and approximately 6 Million people are sick due to COVID-19. There is urgent need of VACCINE of COVID-19 Pandemic and there is news that may be Vaccine could be available in December 2020 or later. The lesson learned is that we in Twenty first century do not have capability to develop immediate Medicines or Vaccines for new disease. We need to study more and Medical Science need more hard work to learn the diseases and their treatment.

\section{References}

1. Ewen Callaway (2020) The Race for Coronavirus Vaccines: A Graphical Guide. NATURE Journal 580(7805): 576-577. 
2. Tung Le, Zacharias Andreadakis, Arun Kumar, Raul Gomez Roman, Stig Tollefsen, et al. (2020) The COVID-19 Vaccine Development Landscape. Nature Reviews Drug Discovery 19(5): 305-306.

3. Nicole Lurie, Melanie Saville, Richard H (2020) Developing Covid-19 Vaccines at Pandemic Speed. The New England Journal of Medicine 382(21): 1969-1973.

4. Richard Lane (2020) Sarah Gilbert: Carving a Path Towards a COVID-19 Vaccine. LANCET London England 395(10232): 1247.

5. Gavin Yamey, Marco Schäferhoff, Richard H, M Pate, Feng Z, et al. (2020) Ensuring Global Access to COVID-19 Vaccines. LANCET London England 395(10234): 1405-1406.

6. (2020) COCONEL Group, A Future Vaccination Campaign Against COVID-19 at Risk of Vaccine Hesitancy and Politicization. The Lancet Infectious Diseases S1473-3099(20) 30426-6.

7. Krishna Ella, V Mohan (2020) Coronavirus Vaccine: Light at the End of the Tunnel. Indian Paediatrics Journal 57(5): 407-410.

8. Qiang Gao, Linlin Bao, Haiyan M, Ling Wang, K Xu, et al. (2020) Rapid Development of an Inactivated Vaccine Candidate for SARS-CoV-2. SCIENCE New York NY, USA.

9. Michael Diamond, Theodore Pierson (2020) The Challenges of Vaccine Development Against a New Virus During a Pandemic. Cell Host and Microbe 27(5): 699-703.

10. Limin Yang, Deyu Tian, Wenjun Liu (2020) Strategies for Vaccine Development of COVID-19. CNKI net Review 36(4): 593-604.

11. Eakachai Prompetchara, ChutitornKetloy, TanapatPalaga (2020) Immune Responses in COVID-19 and Potential Vaccines: Lessons Learned from SARS and MERS Epidemic. Asian Pacific Journal of Allergy and Immunology 38(1): 1-9.

12. Mohammed Uddin, Farah Mustafa, Tahir Rizvi, Tom Loney, Hanan $\mathrm{Al}$, et al. (2020) SARS-CoV-2/COVID-19: Viral Genomics, Epidemiology, Vaccines, and Therapeutic Interventions. MDPI Viruses 12(5): E526.

ISSN: $2574-1241$

DOI: 10.26717/BJSTR.2020.28.004623

Ahsan Ali Siddiqui. Biomed J Sci \& Tech Res

(C) This work is licensed under Creative

Submission Link: https://biomedres.us/submit-manuscript.php
13. Dae Gyun Ahn, Hye Jin Shin, Mi Hwa Kim, Lee S, Kim HS, et al. (2020) Current Status of Epidemiology, Diagnosis, Therapeutics, and Vaccines for Novel Coronavirus Disease 2019 (COVID-19). The Journal of Microbiology and Biotechnology (JMB) 30(3): 313-324.

14. Haneen Amawi, Ghina'aDeiab, AlaaAljabali, et al. (2020) COVID-19 Pandemic: An Overview of Epidemiology, Pathogenesis, Diagnostics and Potential Vaccines and Therapeutics. Future Science, Therapeutic delivery 11(4): 245-268.

15. Zi Wei Ye, Dong Yan Jin (2020) Diagnosis, Treatment, Control and Prevention of SARS-CoV-2 and Coronavirus Disease 2019: Back to the Future. CNKI net, Chinese Journal of Biotechnology 36(4): 571-592.

16. Yuxin Yan, Woo Shin, Yoong Pang, Yang Meng, J lai, et al. (2020) The First 75 Days of Novel Coronavirus (SARS-CoV-2) Outbreak: Recent Advances, Prevention, and Treatment. MDPI International Journal of Environmental Research and Public Health 17(7): 2323.

17. Petra Zimmermann, Nigel Curtis (2020) Coronavirus Infections in Children Including COVID-19: An Overview of the Epidemiology, Clinical Features, Diagnosis, Treatment and Prevention Options in Children. The Pediatric Infectious Disease Journal 39(5): 355-368.

18. Jon Cohen (2020) Vaccine Designers Take First Shots at COVID-19. Science New York 368(6486): 14-16.

19. Sarah Caddy (2020) Developing a Vaccine for covid-19. BMJ Clinical Research Edition 369: m1790.

20. Barney Graham (2020) Rapid COVID-19 Vaccine Development. Science New York, 368(6494): 945-946.

21. Ritesh Gupta, Amerta Ghosh, Awadhesh Singh (2020) Clinical Considerations for Patients with Diabetes in Times of COVID-19 Epidemic. Diabetes and Metabolic Sndrome 14(3): 211-212.

22. (2006) IBM. IBM SPSS Software USA.

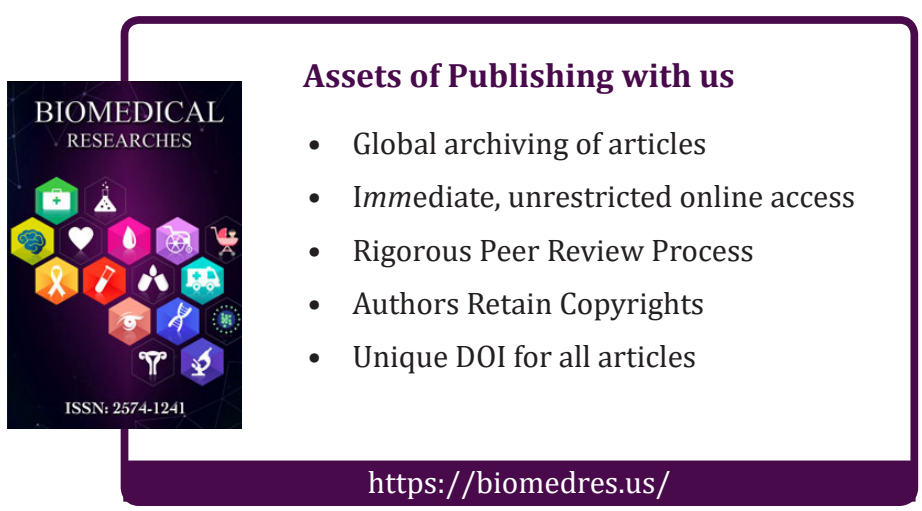

